Article

\title{
Adolescent Perception of Maternal Practices in Portugal and Spain: Similarities and Differences
}

\author{
Bárbara Lorence $^{1, *(\mathbb{D}}$, Cristina Nunes ${ }^{2} \mathbb{D}$, Susana Menéndez $\left.{ }^{3} \mathbb{(}\right)$, Javier Pérez-Padilla ${ }^{4}(\mathbb{C}$ and \\ Victoria Hidalgo ${ }^{1}$ (D) \\ 1 Faculty of Psychology, University of Seville, 41004 Seville, Spain; victoria@us.es \\ 2 Psychology Research Centre (CIP-UAL), University of Algarve, 8005-139 Faro, Portugal; csnunes@ualg.pt \\ 3 Faculty of Education, Psychology and Sports Sciences, University of Huelva, 21007 Huelva, Spain; \\ menendez@uhu.es \\ 4 Faculty of Humanities and Education Sciences, University of Jaen, 23071 Jaen, Spain; jppadill@ujaen.es \\ * Correspondence: bll@us.es
}

Received: 23 June 2020; Accepted: 21 July 2020; Published: 22 July 2020

check for updates

\begin{abstract}
The aim of this study was to compare parenting in two southern European countries, Spain and Portugal, according to adolescent perceptions from a situated perspective. A total of 445 Portuguese $(58.88 \%)$ and Spanish $(41.12 \%)$ adolescents completed a questionnaire about maternal practices and provided socio-demographic information. Portuguese and Spanish mothers were more responsive than coercive in controlling adolescents' compliance and non-compliance situations. Spanish mothers scolded, revoked privileges, and punished physically more often than Portuguese mothers, who used dialogue more often. Multivariate analysis showed three groups of parenting practices. Portuguese mothers were represented mainly in the Indulgent group (81.70\%), and Spanish mothers in the Authoritative group (74.40\%), whereas the third group (Neglectful) was independent of the country of origin. These results support the theory that research and family intervention should recognize cultural aspects in order to grasp the parenting process.
\end{abstract}

Keywords: adolescents; parenting styles; cross-cultural studies; mothers

\section{Introduction}

Cultural comparisons of parenting have aroused the interest of many researchers [1]. Comparative studies of parenting have been conducted in southern Europe, but this research approach is still scarce in Spain and Portugal. The data in this study provide insights into the differences and similarities in parenting between these two countries from adolescents' perspectives, according to the theoretical model of Musitu and Garcia [2].

\subsection{Parenting: Conceptual and Methodological Issues, and Associated Psychosocial Characteristics}

Parental socialization refers to interactive family processes that transmit values, norms, and beliefs to children. Although socialization during adolescence occurs in various contexts, the family continues being important because it plays a key role in adolescent development [3].

Traditionally, parental socialization has been analyzed through dimensional and typology approaches [4,5]. Darling and Steinberg [6] claimed that parenting style, as an emotional climate, must be differentiated from parental practices. Parental practices are specific behaviors used by parents to socialize their children. There are active parental behaviors (e.g., affection, positive parenting, monitoring, dialogue, physical coercion, deprivation, and verbal coercion) and passive behaviors (e.g., indifference and displeasure). Likewise, some of these practices are considered positive (e.g., dialogue, affection) and others negative (physical coercion, indifference) for personal adjustment. 
A review of the literature on this topic shows that a relatively large body of knowledge has accumulated for two major dimensions of parenting styles [7]: warmth (or support) and control (or demandingness). Maccoby and Martin [5] suggested four parenting styles based on these dimensions. The theoretical framework proposed by these authors became the referential model for parenting.

Based on Maccoby and Martin's framework [5], Musitu and García [2] proposed a theoretical parenting model based on two dimensions, with different parental practices combined in each dimension: acceptance/involvement (e.g., responsiveness and dialogue) and strictness/imposition (e.g., scolding and physical punishment). These authors defined four parenting styles by combining the two dimensions described above: authoritative (high acceptance/involvement and strictness/imposition), indulgent (high acceptance/involvement but low strictness/imposition), authoritarian (high strictness/imposition but low acceptance/involvement), and neglectful (low acceptance/involvement and strictness/imposition).

Although these studies improved the available knowledge on parenting, researchers currently demand a more situational approach to parental socialization [8-10]. The present research aimed to advance this line of inquiry by assessing the general pattern of parents' socialization according to parents' behavior in specific daily situations with their children. A broad range of tools was available for assessing parents' educational behavior, but only a few incorporate educative situations. The Parental Socialization Scale for Adolescents, based on the theoretical framework of Musitu and García [2], evaluates everyday parental practices. This instrument consults adolescents (not parents) as informants in assessing parenting. Many empirical studies prefer adolescents' reports because they are less influenced by social desirability than those of parents [11,12]. In fact, adolescent perceptions present a higher predictive power for adjustment indicators than parental reports [13].

Although there is not a total agreement in the literature, parenting practices tend to vary according to adolescent characteristics, such as age $[14,15]$ and gender [16]. They also seem to differ according to parental characteristics, such as gender [1,17], education level [1,18], upbringing [19], and employment [20]. Finally, family-associated characteristics-such as income [21] or unsafe neighborhood [22] have been related to parenting practices. These associations should be taken into account in parenting studies in order to check for potential effects.

Finally, the relationship between parenting practices and well-being and psychosocial outcomes in adolescents has been studied widely. In general, the sons and daughters of authoritative and indulgent parents have better outcomes than those of authoritarian and neglectful parents [23,24]. Researchers agree about the benefits of acceptance and involvement, but strictness and imposition are controversial [25]. Some studies have shown that coercive parental practices (physical, verbal, or psychological) are associated with psychological maladjustment [11,26]. Recently, a meta-analysis of 1435 studies has evidenced that the associations between parenting and adolescents' externalizing problems are in most cases bidirectional and cannot be interpreted exclusively as an effect of parenting on the outcome [27]. Others studies have observed that this relationship depends on the sociocultural factors of the context [28]. Thus, coercive and authoritarian practices show the greatest discrepancy among cultures $[24,29,30]$. Empirical evidence suggests that some combinations of practices could be associated with different consequences in different sociocultural contexts [31-33].

\subsection{Cultural Characteristics Associated with Parenting}

Since the seminal works of Super and Harkness [34], culture has played an important role in the study and characterization of parental socialization [35,36]. The diversity of findings across cultural groups has led to the re-emergence of the study of parenting in cultural niches [37]. Cross-cultural studies about parenting have been focused on examining the frequency of use of parenting practices $[30,33,38]$ and their effects on child and youth development $[1,39,40]$.

The general aim of the present study is to examine parenting practices in Spain and Portugal searching for similarities and differences between both countries. In general, Portugal and Spain share many cultural and political similarities. These two countries have been traditionally characterized as 
collectivist countries and are two of the European countries that allocate fewer funds to family-related policies [41]. Similar to other southern European countries, family values are deeply rooted in Spain and Portugal [42]. Thus, individuals from both countries place great value on family, and family unity is a source of basic support in their lives [43]. This is in line with findings presented by an HBSC project showing similar proportions of adolescents who reported living with both parents [44]. Additionally, empirical data show high family cohesion, parental support, and family satisfaction in both Portugal and Spain [45]. In contrast, the European Social Survey [46], a comparative longitudinal study of more than 20 countries, showed differences between Spain and Portugal that advanced our understanding of parental socialization. For example, Portuguese children were the last to become financially independent, and when they did so, the main purpose was to create a new family. Portuguese youths become parents at an earlier age, and the rate of female employment was higher in Portugal. Lastly, the UNICEF Office of Research [47], suggests differences of well-being between Portuguese and Spanish youth. This report ranks Spain 24th in Adolescent Life Satisfaction (lowest third) and Portugal 18th (highest third). However, these differences are not observed in other studies on perceived quality of life [48,49]. With regard to parenting, comparative studies have been carried out between European countries [1,31] Some differences were found in parenting practices between these two countries in a transcultural study (Spain, Portugal, and Colombia). Resulting from a discriminative analysis, a set of variables from the three countries showed that Portuguese parents were less overprotective and displayed less parental control than parents in Spain [50]. In contrast, Portuguese parents exhibited more positive parenting, psychological control, and behavior control than parents from the Netherlands [31]. A recent study has analyzed the distribution of parenting styles among the Spanish and Portuguese, but focused on emerging adults between 18-30 years old and no adolescents [40]. In relation to the effects of parental socialization on adolescent outcomes, results were similar in both countries. Recent studies [51] have proposed a paradigm of three different historical stages for optimal parental style with data of adolescents from different countries. According to this study, in the current digital era the indulgent and authoritative styles are the optimal styles, especially the indulgent one, whereas those from neglectful and authoritarian homes were associated with poor adolescent adjustment. These results are also reported in studies carried out in Spain and Portugal $[24,35,36,52-54]$.

Finally, there is evidence that different sociocultural characteristics in Portugal and Spain may affect parental values and behavior, but comparative research between the two countries is incomplete. The present study examined parenting practices in Spain and Portugal through multiple approaches, including intragroup analysis, an intergroup comparison, and a person-oriented strategy. It was expected that there would be more similarities than differences in the parenting behaviors of parents in Spain and Portugal in compliance and non-compliance situations. Specifically, it was expected that acceptance/involvement would predominate in both countries, but with more parental control in Spain.

\section{Materials and Methods}

\subsection{Participants}

A total of 445 Spanish and Portuguese adolescents participated in this research. The Spanish sample was composed of 183 adolescents, $49 \%$ girls and $51 \%$ boys, from public schools in Andalusia (southern Spain). The mean age was 13.83 years $(S D=2.02)$, distributed as follows: $36.61 \%$ aged $11-12$ years, $38.25 \%$ aged $13-15$ years, and $25.14 \%$ aged $16-17$ years. The mean number of children per family was $1.50(S D=1.14)$. The mean age of the mothers was 43.03 years $(S D=5.11)$. Among the mothers, $35.52 \%$ completed primary school (low educational level), $34.97 \%$ finished secondary school (medium educational level), and $29.51 \%$ had university education (high educational level). The percentage of employed mothers was $65.17 \%$. Single mothers accounted for $8.74 \%$ of the sample. 
The Portuguese sample was composed of 262 adolescents, $54.96 \%$ girls and $45.04 \%$ boys, from public schools in the Algarve (southern Portugal). The mean age was 13.94 years $(S D=2.04)$, distributed as $33.21 \%$ aged $11-12$ years, $39.69 \%$ aged $13-15$ years, and $27.10 \%$ aged $16-17$ years. The number of children per family was $1.37(S D=1.13)$. The mean age of the Portuguese mothers was 40.89 years $(S D=5.73)$, and their educational levels were distributed as follows: low $(13.74 \%)$, medium $(61.45 \%)$, and high $(24.81 \%)$. The percentage of employed mothers was $96.95 \%$. Single mothers accounted for $26.48 \%$ of the sample.

Both samples were similar in the adolescents' age $\left(\chi^{2}[2, N=445]=0.576, p=0.350\right)$, gender $\left(\chi^{2}[1, N=445]=1.22, p=0.269\right)$, and number of children per family $(F[1,444]=1.38, p=0.241)$.

The two groups differed in mothers' characteristics. Spanish mothers were significantly older than Portuguese mothers $(F[1,442]=16.16, p<0.001)$, and Portuguese mothers had higher educational attainment than did Spanish mothers $\left(\chi^{2}[2, \mathrm{~N}=445]=38.34, p<0.001 ; V_{\text {Cramer }}=0.294\right)$.

Work status varied significantly between the countries $\left(\chi^{2}[1, N=440]=77.75, p<0.001\right.$; $\Phi=0.426$ ). There was a smaller percentage of employed Spanish mothers than Portuguese mothers. Finally, more of the Portuguese mothers were single $\left(\chi^{2}[1, N=436]=20.54, p<0.001 ; \Phi=0.223\right)$.

\subsection{Measures}

The Parental Socialization Scale for Adolescents (ESPA-29) [2] evaluates parental socialization in compliance situations, in which adolescents behave according to parental expectations or rules, and non-compliance situations, in which adolescents disobey or behave inappropriately.

The ESPA-29 presents 13 compliance situations (e.g., 'a teacher calls your mother and tells her that you are behaving well in class') and 16 non-compliance situations (e.g., 'you arrive home late'). In each of the compliance situations, the adolescent rated the parent's affection (e.g., 'my mother shows affection') and indifference (e.g., 'my mother seems indifferent'). In each of the non-compliance situations, the adolescent rated the parent's dialogue (e.g., 'my mother talks to me'), detachment (e.g., 'my mother doesn't say anything to me'), scolding (e.g., 'my mother scolds me'), physical punishment (e.g., 'my mother spanks me'), and revoking of privileges (e.g., 'my mother takes something away from me'). The questionnaire consisted of 116 items to be rated from 1 (never) to 4 (always), covering two parenting dimensions:

- Acceptance/involvement, which was obtained by averaging the responses on affection, dialogue, indifference, and detachment (the last two subscales were reverse-coded);

- Strictness/imposition, which was calculated by averaging the responses on scolding, physical punishment, and revoking privileges.

The mean time to complete the ESPA-29 questionnaire is approximately $30 \mathrm{~min}$ per parent. To minimize the time required by the participants, the present study asked the adolescents only about maternal practices.

The ESPA-29 questionnaire was validated for Spanish [55] and Portuguese populations [56]. In this study, the reliability indices for acceptance/involvement were $H=0.77$ (Spain) and $H=0.78$ (Portugal), and those for strictness/imposition were $H=0.80$ (Spain) and $H=0.74$ (Portugal). With regard to the subscales, the internal consistency indices were calculated for both the Spanish sample: affection $(H=0.94)$, dialogue $(H=0.93)$, indifference $(H=0.92)$, detachment $(H=0.91)$, scolding $(H=0.90)$, physical punishment $(H=0.97)$, and revoking privileges $(H=0.93)$; and the Portuguese sample: affection $(H=0.95)$, dialogue $(H=0.93)$, indifference $(H=0.93)$, detachment $(H=0.94)$, scolding $(H=0.94)$, physical punishment $(H=0.97)$, and revoking privileges $(H=0.93)$.

\subsection{Procedure}

A non-experimental design using a cross-sectional, descriptive, and quantitative methodology was used. Informed consent forms were obtained from parents and adolescents. In Seville (Spain), 14 schools were selected, and in the Algarve (Portugal), nine schools were included. The sample 
method (random multistage sampling stratified by conglomerates) allowed for the generalization of the results in both cities. Likewise, the results are representative with respect to age, sex, and type of school (public or private). The random sample of participating schools is taken from a census provided by all education centers of Seville and Algarve. After initial contact with the administration boards by mail and telephone, selected schools were visited, and parental permission was obtained. Adolescents chose freely to participate, had complete confidentiality, and were offered no compensation. Data were collected in a self-administered questionnaire in a paper-and-pencil format. This questionnaire was applied to the whole class during a regular class period in the presence of a trained interviewer. This project was approved by the Scientific Commission of the Psychology and Sciences Education Department, University of the Algarve.

\subsection{Statistical Analyses}

Paired sample t-tests were computed to compare the mean results of parenting practices for each country. Snedecor's $F$ distribution (analysis of variance (ANOVA)) and Cohen's $d$ for the effect size were used to examine cross-cultural differences in continuous variables, and a chi-square test, and $V_{\text {Cramer }}$ and the Yates correction for the effect size for categorical variables. As the assumption of homogeneity of covariance matrices was violated, some multivariate analyses could not be performed.

To analyze the existence of typologies of adolescents regarding parenting practices, a two-step cluster analysis was performed [57]. Cluster analysis is a multivariate classification technique that identifies groups of individual cases defined by similarities in multiple dimensions, so that members of the resulting groups are as similar as possible to others within their group and as different as possible from those in the other groups. Prior to clustering, all selected measures were standardized in order to equate the variables and taking into account that cluster analysis is especially sensitive to the presence of outliers, the Mahalanobis distance was calculated to detect multivariate outliers [58]. The influential outliers detected were removed. Initial groupings were explored through hierarchical cluster analysis, with squared Euclidean distance and Ward's method as the measures of linkage. The decision about the number of clusters was based on the agglomeration coefficients, statistical validity, size, and meaningfulness of the clusters. The centroids of these initial clusters were then submitted to an iterative non-hierarchical clustering procedure ( $\mathrm{k}$ means cluster analysis) to confirm and refine final cluster membership. Post hoc comparisons (ANOVA) between clusters were conducted merely for the purposes of interpretation and not to validate the cluster solution [48]. Analyses were processed using IBM SPSS 24.0 [59]

\section{Results}

The results are presented in the form of intragroup analysis (independently for Spain and Portugal), intergroup comparison (between the countries), and comprehensive comparison (Spain and Portugal together).

\subsection{Intragroup Analysis and Intergroup Comparison}

Paired sample $t$-tests were used to compare the most reported parenting practices for each country (intragroup analysis). In compliance situations, adolescents in both countries reported more affection than indifference (Spain: $\mathbf{t}(181)=7.09, p<0.001$; Portugal: $\mathbf{t}(261)=18.00, p<0.001)$. In non-compliance situations, similarities were found in Spain and Portugal.

Ten pairs of contrasts by country were performed; $p<0.005$ was considered significant in order to control for the family-wise type I error. In Spain, the parenting practices used to control adolescent behavior were as follows (in decreasing order): scolding, engaging in dialogue, revoking privileges, practicing detachment, and physical punishment. In Portugal, these corresponding practices were engaging in dialogue, scolding, revoking privileges, practicing detachment, and physical punishment. Values of $p<0.005$ were obtained for all paired contrasts, with the exception of scolding/dialogue in 
Spain $(p=0.048)$ and revoking privileges/detachment in Portugal $(p=0.098)$. The descriptive data for parenting practices in compliance and non-compliance situations are presented in Table 1.

Table 1. Descriptives and ANOVAs for Parenting Practices between Countries.

\begin{tabular}{ccccc}
\hline $\boldsymbol{M}(\boldsymbol{S D})$ & Spain & Portugal & $\boldsymbol{F}$ & $\boldsymbol{d}^{\mathbf{n}}$ \\
\hline Compliance situations & & & & \\
Affection & $2.71(0.69)$ & $2.95(0.76)$ & $12.08^{* * * *}$ & 0.33 \\
Indifference & $2.00(0.70)$ & $1.63(0.60)$ & $36.69^{* * * *}$ & 0.57 \\
Non-compliance situations & & & \\
Dialogue & $2.58(0.67)$ & $2.70(0.70)$ & $\mathrm{ns}$ & \\
Detachment & $1.30(0.30)$ & $1.51(0.53)$ & $22.86^{* * * *}$ & 0.49 \\
Verbal Scolding & $2.72(0.58)$ & $1.81(0.62)$ & $245.04^{* * * *}$ & 1.52 \\
Physical Punishment & $1.15(0.28)$ & $1.16(0.33)$ & $\mathrm{ns}$ & \\
Revoking Privileges & $2.11(0.66)$ & $1.58(0.53)$ & $87.65^{* * *}$ & 0.88 \\
\hline
\end{tabular}

ns $=$ Not Significant, ${ }^{*} p<0.05,{ }^{* *} p<0.01,{ }^{* * *} p<0.005,{ }^{* * * *} p<0.001$. Note: $<0.01$ negligible, $>0.01$ and $<0.09$ low,

$>0.09$ and $<0.25$ moderate, $>0.25$ high.

Comparative analyses of parenting practices between both countries were performed (intergroup comparison). ANOVAs were computed to examine possible differences between Portugal and Spain in parenting practices in compliance and non-compliance situations.

Regarding compliance situations, the results revealed that Portuguese adolescents perceived more maternal affection and lower indifference than did Spanish adolescents. With respect to non-compliance situations, Spanish adolescents indicated more maternal scolding and revoking privileges to control their behavior than did Portuguese adolescents. Both countries presented similar data for dialogue and physical punishment.

\subsection{Comprehensive Analysis of Parenting Practices}

Cluster analysis was used to categorize 445 Spanish and Portuguese adolescents according to seven parenting practices. Nine outliers were identified and eliminated from this analysis. No problems of collinearity were found (Table 2), and the correlation coefficients between parenting practice scores did not exceed the recommended limit of $r=0.80$ [59].

Table 2. Pearson Correlation Coefficients of Parenting Practices.

\begin{tabular}{ccccccc}
\hline & $\mathbf{1}$ & $\mathbf{2}$ & $\mathbf{3}$ & $\mathbf{4}$ & $\mathbf{5}$ & $\mathbf{6}$ \\
\hline 1. Affection & - & & & & & \\
\hline 2. Indifference & $-0.69^{* * * *}$ & - & & & & \\
\hline 3. Dialogue & $0.52^{* * * *}$ & $-0.29^{* * * *}$ & - & & & \\
\hline 4. Detachment & $-0.29^{* * * *}$ & $0.36^{* * * *}$ & $-0.23^{* * * *}$ & - & & \\
\hline 5. Verbal Scolding & $-0.14^{* * *}$ & $0.30^{* * * *}$ & $-0.11^{*}$ & $-0.10^{*}$ & - & - \\
\hline 6. Physical Punishment & -0.01 & 0.09 & $-0.12^{* *}$ & $0.24^{* * * *}$ & $0.31^{* * * *}$ & - \\
\hline 7. Revoking Privileges & 0.08 & $0.04^{* * *}$ & -0.01 & $-0.12^{* *}$ & $0.61^{* * * *}$ & $0.40^{* * * *}$ \\
\hline & $* p<0.05^{* *} p<0.01^{* * *} p<0.005^{* * * *} p<0.001$. & &
\end{tabular}

First, hierarchical cluster analysis was performed using Ward's method. The Euclidean distances between large increases in coefficients among agglomerations were examined. Table 3 summarizes the results for the agglomeration coefficient from cluster 10 to cluster 1 . The agglomeration coefficient showed large increases from clusters 4 to 3 (22.97\% increase), from clusters 3 to 2 (28.98\% increase), and from clusters 2 to 1 ( $34.83 \%$ increase). Statistical validity, cluster size, and meaningfulness of the clusters revealed that the 3 -cluster solution presented the best fit for distribution per cluster. 
Table 3. Agglomeration Coefficient from Clusters 10 to 1.

\begin{tabular}{ccc}
\hline Number of Cluster & Agglomeration Coefficient & $\begin{array}{c}\text { Percentage of Change in } \\
\text { Coefficient to Next Level }\end{array}$ \\
\hline 10 & 3.93 & 2.54 \\
9 & 4.03 & 2.23 \\
8 & 4.12 & 9.46 \\
7 & 4.51 & 1.99 \\
6 & 4.60 & 4.13 \\
5 & 4.79 & 5.43 \\
4 & 5.05 & 22.97 \\
3 & 6.21 & 28.98 \\
2 & 8.01 & 34.83 \\
1 & 10.80 & \\
\hline
\end{tabular}

After determining the number of clusters through the hierarchical method, non-hierarchical analysis (k-means) was performed to confirm the 3-cluster solution. The mean cluster values for each variable of this solution are presented in Table 4 . The results revealed three clusters of different sizes and behavioral configurations: (C1) neglectful (36.09\%); (C2) authoritative (28.74\%); and (C3) indulgent $(35.17 \%)$. The names of the groups were based on parenting practices. These names were mainly a mnemonic device and not intended to oversimplify the differences or similarities between or within groups.

Table 4. Means Contrasts of 3-Cluster Solution.

\begin{tabular}{|c|c|c|c|c|c|}
\hline$M(S D)$ & $\begin{array}{l}\text { Neglectful }^{1} \\
\quad(n=157)\end{array}$ & $\begin{array}{l}\text { Authoritative }^{2} \\
\quad(n=125)\end{array}$ & $\begin{array}{c}\text { Indulgent }^{3} \\
(n=153)\end{array}$ & $F$ & $\begin{array}{l}\text { Post-hoc } \\
\text { (DMS)n }^{n}\end{array}$ \\
\hline Affection & $2.27(0.54)$ & $2.85(0.59)$ & $3.47(0.45)$ & $201.42 * * * *$ & $\begin{array}{l}1<2 \\
1<3 \\
2<3\end{array}$ \\
\hline Indifference & $2.13(0.65)$ & $1.89(0.56)$ & $1.28(0.30)$ & $104.77^{* * * *}$ & $\begin{array}{l}1>2 \\
1>3 \\
2>3\end{array}$ \\
\hline Dialogue & $2.16(0.55)$ & $2.68(0.59)$ & $3.13(0.51)$ & $122.95^{* * * *}$ & $\begin{array}{l}1<2 \\
1<3 \\
2<3\end{array}$ \\
\hline Detachment & $1.61(0.44$ & $1.29(0.37)$ & $1.27(0.32)$ & $37.62 * * * *$ & $\begin{array}{l}1>2 \\
1>3\end{array}$ \\
\hline Verbal Scolding & $2.01(0.54)$ & $3.03(0.43)$ & $1.69(0.52)$ & $256.18^{* * * *}$ & $\begin{array}{l}1<2 \\
1>3 \\
2>3\end{array}$ \\
\hline Physical Punishment & $1.11(0.19)$ & $1.32(0.42)$ & $1.05(0.12)$ & $39.61^{* * * *}$ & $\begin{array}{l}1<2 \\
2>3\end{array}$ \\
\hline Revoking Privileges & $1.48(0.38)$ & $2.50(0.55)$ & $1.55(0.45)$ & $204.17^{* * * *}$ & $\begin{array}{l}1<2 \\
2>3\end{array}$ \\
\hline
\end{tabular}

${ }^{\mathrm{n}}$ Note. Post-hoc analysis: All pair contrasts presented in Table obtained a ${ }^{* * * *} p<0.001$.

The descriptive data and Snedecor's F test are presented in Table 4. The scores for affection, indifference, dialogue, and scolding differed significantly among the three clusters (family-wise type I error was controlled, with $p<0.017$ ). Taking into account the comparison between groups (post-hoc analysis), clusters were defined. Negligent mothers presented low levels of affection and dialogue, high levels of indifference and detachment, and moderate levels of verbal scolding and revoking privileges. Regarding physical punishment, the negligent mothers presented similar scores to indulgent mothers. In addition, the cluster of indulgent mothers was characterized by low indifference, 
verbal scolding, and revoking privileges, as well as high levels of affection and dialogue. The group of indulgent and authoritarian mothers showed low levels of detachment. In addition, the authoritarian mothers were characterized by moderate levels of affection, dialogue, and indifference and high levels of verbal scolding, physical punishment, and revoking privileges. It is important to note that, despite the differences found between clusters, scores of physical punishment are very low in all the clusters.

The configuration of the three clusters was associated with country of origin $\left(\chi^{2}[2, N=435]=89.87\right.$, $p<0.001)$. The analysis of standardized residuals showed that there were no significant differences between the country of the adolescents and the negligent cluster but in the authoritative cluster (Spain: $74.40 \%$; Portugal: $25.60 \%$ ) and in the indulgent cluster (Spain: $18.30 \%$; Portugal: $81.70 \%$ ) a differentiated distribution was observed.

Finally, chi-square tests and two-way factorial ANOVA were performed to analyze the composition of the clusters according to specific sociodemographic characteristics. This analysis was done because the distribution of countries differed in marital status, labor status, educational level, and age. Thus, the dependent variables were each of the categories within each dimension, and the independent ones were country and cluster (Table 5).

Table 5. Contrasts of 3-Cluster Solution between Spain and Portugal according to Sociodemographic Characteristics.

\begin{tabular}{|c|c|c|c|c|c|c|}
\hline $\begin{array}{c}\text { Spain/ } \\
\text { Portugal }\end{array}$ & Neglectful & Authoritative & Indulgent & \multicolumn{3}{|c|}{ Statistics } \\
\hline \multicolumn{7}{|c|}{ Categorical variables (Residuals adjusted standardized) } \\
\hline \multicolumn{7}{|l|}{ Marital status } \\
\hline Single & $-0.1^{\mathrm{s}} / 0.1^{\mathrm{p}}$ & $2.4^{\mathrm{s}} /-2.4^{\mathrm{P}}$ & $-1.9^{\mathrm{s}} / 1.9 \mathrm{p}$ & \multicolumn{3}{|c|}{$\chi^{2}(2, N=82)=6.77, p=0.034, V_{\text {Cramer }}=0.287$} \\
\hline Couple & $-0.5^{\mathrm{s}} / 0.5^{\mathrm{p}}$ & $7.7^{\mathrm{s}} /-7.7^{\mathrm{P}}$ & $-7.1^{\mathrm{s}} / 7.1^{\mathrm{P}}$ & \multicolumn{3}{|c|}{$\chi^{2}(2, N=345)=74.43, p<0.001, V_{\text {Cramer }}=0.464$} \\
\hline \multicolumn{7}{|l|}{ Labor status } \\
\hline Employed & $-0.6^{\mathrm{s}} / 0.6^{\mathrm{p}}$ & $7.7^{\mathrm{s}} /-7.7^{\mathrm{P}}$ & $-6.3^{\mathrm{s}} / 6.3^{p}$ & \multicolumn{3}{|c|}{$\chi^{2}(2, N=361)=69.67, p<0.001, V_{\text {Cramer }}=0.439$} \\
\hline Non-Employed & $-0.9^{\mathrm{s}} / 0.9^{\mathrm{p}}$ & $2.6^{\mathrm{s}} /-2.6^{\mathrm{P}}$ & $-2.2^{\mathrm{s}} / 2.2^{\mathrm{p}}$ & \multicolumn{3}{|c|}{$\chi^{2}(2, N=69)=8.34, p=0.015, V_{\text {Cramer }}=0.015$} \\
\hline \multicolumn{7}{|l|}{ Educational level } \\
\hline Low & $-0.7^{\mathrm{s}} / 0.7^{\mathrm{p}}$ & $4.6^{\mathrm{s}} /-4.6^{\mathrm{p}}$ & $-4.1^{\mathrm{s}} / 4.1^{\mathrm{p}}$ & \multicolumn{3}{|c|}{$\chi^{2}(2, N=100)=26.60, p<0.001, V_{\text {Cramer }}=0.516$} \\
\hline Medium & $-0.5^{\mathrm{s}} / 0.5^{\mathrm{p}}$ & $6.1^{\mathrm{s}} /-6.1^{\mathrm{P}}$ & $-4.6^{\mathrm{s}} / 4.6^{\mathrm{p}}$ & \multicolumn{3}{|c|}{$\chi^{2}(2, N=220)=42.54, p<0.001, V_{\text {Cramer }}=0.440$} \\
\hline \multirow[t]{2}{*}{ High } & $-0.2^{\mathrm{s}} / 0.2^{\mathrm{p}}$ & $3.6^{\mathrm{s}} /-3.6^{\mathrm{p}}$ & $-3.5^{\mathrm{s}} / 3.5^{\mathrm{p}}$ & \multicolumn{3}{|c|}{$\chi^{2}(2, N=115)=16.51, p<0.001, V_{\text {Cramer }}=0.379$} \\
\hline & \multicolumn{2}{|c|}{ Continuous variables (Means) } & & & & \\
\hline Age & $\begin{array}{c}43.75^{\mathrm{s}} / 41.49 \\
\mathrm{p}\end{array}$ & $42.5^{\mathrm{s}} / 39.63^{\mathrm{P}}$ & & \multicolumn{3}{|c|}{$43.11^{\mathrm{s}} / 40.81^{\mathrm{P}}$} \\
\hline & & & & $D f$ & $F$ & $p$ \\
\hline & & $\begin{array}{l}\text { Corrected model } \\
\text { Country } \\
\text { Cluster } \\
\text { Country }{ }^{*} \text { Cluster } \\
\text { R Squared }=0.045\end{array}$ & & $\begin{array}{l}5 \\
1 \\
2 \\
2\end{array}$ & $\begin{array}{c}4.06 \\
16.36 \\
2.33 \\
0.11\end{array}$ & $\begin{array}{l}0.001 \\
0.000 \\
0.098 \\
0.898\end{array}$ \\
\hline
\end{tabular}

Note. ${ }^{\mathrm{s}}$ corresponds to Spanish sample and $\mathrm{P}$ corresponds to Portuguese sample.

The degree of association between variables (1.96) was performed using the corrected standardized residuals obtained from contingency tables in categorical or nominal variables. In the cluster of neglectful mothers, no significant difference was observed between the selected socio-demographic data. However, in the authoritative and indulgent clusters, the distribution of results in terms of sociodemographic data is similar to that found in the samples of each country. With respect to the age of the mothers, two-way factorial ANOVA was performed, with cluster and country as fixed factors; the results showed a significant effect only for country.

After these analyses, the findings showed that Spanish mothers were represented mainly in the authoritative group ( $51.10 \%$ of the sample of Spanish mothers), and Portuguese mothers were represented in the indulgent group $(49.41 \%)$, independently of their marital, employment, age, or educational status (Figure 1). 


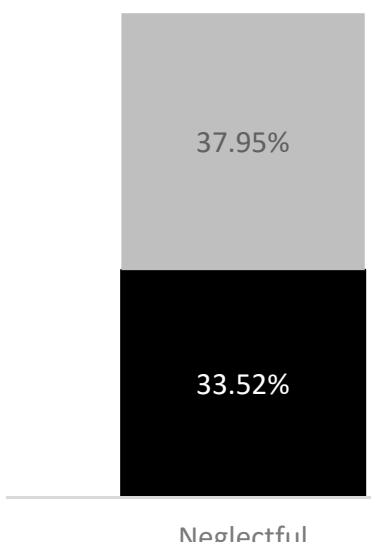

Neglectful

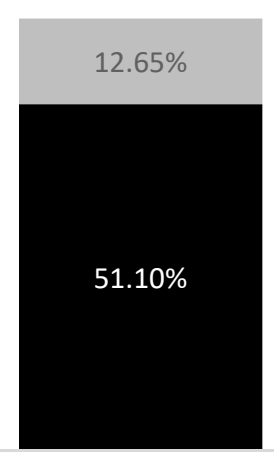

Authoritative

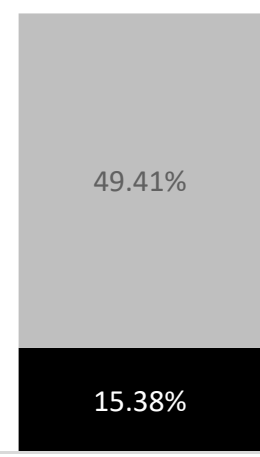

Indulgent

Figure 1. Distribution of the Spanish and Portuguese samples according to the clusters.

\section{Discussion}

The aim of the present study was to examine maternal parenting practices in Spanish and Portuguese families. In this investigation, we used multiple analyses, including intragroup and intergroup comparisons, and comprehensive and person-oriented strategies. The results, which showed similarities and differences regarding adolescents' perceptions of mothers' parenting in Spain and Portugal, are discussed below.

In the intragroup analysis, and in accordance with our expectations, important similarities were found between countries. Spanish and Portuguese mothers were more responsive than coercive. In compliance situations, mothers from both countries used more affectionate practices than indifferent ones. In non-compliance situations, dialogue was one of the most common strategies used to control adolescent behavior, and physical punishment was used the least in both countries. These results are consistent with those of previous studies that used different approaches in southern European countries. Parents from these countries practiced more affection, acceptance, and involvement in children's socialization than strictness and firm control, which were perceived in a negative way [24]. Specifically, Spanish and Portuguese families were characterized by good relationships, significant support, and acceptable levels of control [45]. Sociological studies have found that familism is more frequent than individualism in Spain and Portugal [42,43]. These results are important, because warmth and communication are key aspects in optimal parenting. Specifically, the combination of high parental warmth and involvement and low strictness appears to be the best parenting strategy for adolescent adjustment in southern European countries [23,24,60,61].

In this study, comparative analyses of parenting practices between both countries examined possible differences in compliance and non-compliance situations. The results showed that Portuguese mothers were more active in compliance situations (provided more positive reinforcement for appropriate behavior), whereas Spanish mothers were more active in non-compliance situations (practiced more scolding and revoking of privileges). It is difficult to reach conclusions about these differences, because to our knowledge, few studies have compared Portuguese and Spanish parenting practices in compliance and non-compliance situations. However, the results from a comparative study of families in Colombia, Portugal, and Spain [50] showed that Portuguese families were characterized by lower parental overprotection and control than Spanish families.

Finally, cluster analysis was performed to examine parenting practices in both countries from a comprehensive and person-oriented approach. The goal of this strategy was to provide a holistic account of the higher-order interactions among variables [62]. The results from this analysis revealed a 
typology of three maternal parenting groups characterized by different socialization profiles, in part similar to the typology proposed by Musitu and García [2]. Specifically, the neglectful cluster was defined by a passive profile, whereas the authoritative and indulgent clusters included mothers who were active in compliance and non-compliance situations. Mothers from the authoritative cluster stood out for their coercive discipline in non-compliance situations. The indulgent cluster grouped mothers who used inductive discipline in non-compliance situations and very active behavior in compliance situations, expressing affection when their sons and daughters behaved appropriately. Although these clusters had a somewhat heterogeneous composition based on the country of origin, the authoritative cluster was for the most part composed of Spanish mothers $(74.40 \%)$, the indulgent cluster contained mostly Portuguese mothers $(81.70 \%)$, and there were no differences in the neglectful cluster. Likewise, although Portuguese and Spanish samples differed in parental sociodemographic variables (age, education, employment, and type of family), it must be underscored that these differences did not explain the differences observed in the composition of clusters.

These results showed similarities and differences between Spain and Portugal. Hence, it must be stressed that, in both countries, the majority of mothers were grouped in the authoritative or the indulgent clusters, which include parenting practices that have been associated with better adolescent adjustment in previous research $[7,24,54,60]$. Physical punishment was low in all clusters. Nevertheless, Spanish mothers were represented $(51.10 \%)$ in the cluster defined by coercive practices. To explain this difference, it should be noted that the ESPA-29 only elicits coercive practices and may not have distinguished other types of controlling strategies that may be characteristic of Portuguese mothers, such as psychological control [31,63]. Moreover, the meaning of verbal coercion in both countries and how it is related to adolescents' adjustment was not specified. The influence of parental control depends on how it is perceived by the child. For example, in China, parental control is not viewed negatively or as restrictive or dominating, but rather is associated with love and caring [28].

Although it is important to note that these data are not representative of the Spanish or Portuguese population, the conclusions of this paper could be applied to these cultures. The main limitations of this study were the small sample size, the fact that the participants were recruited from two specific southern regions of Spain and Portugal, and the fact that the adolescents reported only maternal parenting practices. Future studies are needed to examine the generalizability of the findings in larger and more representative samples. Likewise, it would be helpful to distinguish between paternal and maternal practices. Another limitation was that parenting practices were assessed by only one informant, and parental points of view were not included. Finally, although the employment status of mothers has been considered, the SES has not been included in the analyses as a predictor of parenting practices. Finally, due to non-compliance with parametric assumptions, some multivariate analyses could not be performed.

In general, the findings of cross-cultural studies examining the relationship between parental socialization and personal adjustment have been consistent for affection, showing that this dimension was associated with positive adolescent outcomes. Nevertheless, the results for parental control tend to be controversial, particularly for coercive practices. Two arguments have been proposed to explain this, including empirical approximations [64] and diverse meaning and consequences for adolescent development in different cultural contexts [33].

In conclusion, the maternal parenting typology developed through this study provided useful information about cultural specificities in socialization practices in Portugal and Spain. The results presented here support the growing body of empirical research, which outlines how parenting practices depend on cultural backgrounds $[1,18-21,31,65,66]$. The description of the parental socialization styles characteristic of each country, due to their cultural influence, has implications for interventions. Parenting support programs have currently become a fundamental and widely used resource to promote adequate exercise of parenting [67]. But interventions valid for one culture are not necessarily valid for another, even in neighboring countries, such as Spain and Portugal. Parenting support programs have to be sensitive to cultural differences and promote their dissemination taking into account the 
different characteristics of the participating families. Ignoring the cultural influences that characterize parental practices introduces a significant threat to the effectiveness of these interventions [68].

Finally it should be noted that this study contributes to the parenting literature because (a) it is the first cross-cultural study comparing parenting in Spain and Portugal, (b) it focuses on the cultural influences that characterize parenting practices, thus favoring better adaptation and dissemination of parenting programs, and (c) it has demonstrated the usefulness of a comprehensive and person-oriented approach to identifying parenting styles in southern European countries. Moreover, differentiating between domains of parenting behavior may have been a more fine-grained approach than the general typologies assessed in most studies. According to Grusec and Davidov [10], parenting behaviors can be effective only when they are appropriately matched with the domain of interaction (i.e., protection, reciprocity, control, guided learning, and group participation). In other words, suitable parenting involves responding in a way that is perceived as appropriate by the adolescent and requires different parental behaviors in each domain. Future research should recognize these aspects in order to fully grasp the complex parenting process.

Author Contributions: Conceptualization, B.L., C.N., S.M., and V.H.; formal analysis, B.L. and C.N.; investigation, B.L., C.N., S.M., and V.H.; supervision, B.L., C.N., S.M., and V.H.; methodology, B.L., C.N., and S.M.; resources, B.L. and V.H.; writing—original draft, B.L., C.N., and J.P.-P.; writing—review and editing, B.L., C.N., S.M., V.H., and J.P.-P. All authors have read and agreed to the published version of the manuscript.

Funding: This research was partially funded by the Spanish Government (MINECO, Ministerio de Economía y Competitividad), grant number EDU2013-41441-P. This work was partially funded by national funds through the FCT-Fundação para a Ciência e a Tecnologia—as part of the CIP project-Refa UID/PSI/04345/2020.

Conflicts of Interest: The authors declare no conflict of interest.

\section{References}

1. Olivari, M.G.; Wahn, E.H.; Maridaki-Kassotaki, K.; Antonopoulou, K.; Confalonieri, E. Adolescents perceptions of parenting styles in Sweden, Italy and Greece: An exploratory study. Eur. J. Psychol. 2015, 11, 244-258. [CrossRef]

2. Musitu, G.; García, F. ESPA29: Escala de Socialización Parental en la Adolescencia; [ESPA-29: Parental socialization scale in adolescence]; TEA: Madrid, Spain, 2001.

3. Bornstein, M.H. Handbook of Parenting: Vol.5: Practical Issues in Parenting, 2nd ed.; Lawrence Erlbaum Associates: Mahwah, NJ, USA, 2002.

4. Baumrind, D. Effective parenting during the early adolescent transition. In Family Transitions; Cowan, P.A., Hetherington, M., Eds.; Lawrence Erlbaum Associates: Hillsdale, NJ, USA, 1991; pp. 111-115.

5. Maccoby, E.E.; Martin, J.A. Socialization in the context of the family: Parent-child interaction. In Handbook of Child Psychology, 4th ed.; Vol. 4. Socialization, Personality, and Social Development; Hetherington, E.M., Ed.; Wiley: New York, NY, USA, 1983; Volume 4, pp. 1-10.

6. Darling, N.; Steinberg, L. Parenting style as context: An integrative model. Psychol. Bull. 1993, 113, 487-497. [CrossRef]

7. Carlo, G.; Mestre, M.V.; Samper, P.; Tur, A.; Arment, B.E. The longitudinal relations among dimensions of parenting styles, sympathy, prosocial moral reasoning, and prosocial behaviors. Int. J. Behav. Dev. 2010, 35, 116-124. [CrossRef]

8. Lorence, B.; Menendez, S.; Hidalgo, M. Situational analysis of parental socialization in adolescence. Rev. Cercet. Interv. Soc. 2016, 52, 51-63.

9. Yaffe, Y. Parental authority: A contemporary integrative-theoretical conceptualization. In A Closer Look at Parenting Styles and Practices; Roman, N., Ed.; Nova Science Publishers, Inc.: New York, NY, USA, 2020; pp. 73-96.

10. Grusec, J.E.; Davidov, M. Integrating different perspectives on socialization theory and research: A domain-specific approach. Child Dev. 2010, 81, 687-709. [CrossRef]

11. Bogenschneider, K.; Pallock, L. Responsiveness in parent adolescent relationships: Are influences conditional? Does the reporter matter? J. Marriage Fam. 2008, 70, 1015-1029. [CrossRef] 
12. Gonzales, N.A.; Cauce, A.M.; Mason, C.A. Interobserver agreement in the assessment of parental behavior and parent-adolescent conflict: African American mothers, daughters, and independent observers. Child Dev. 1996, 67, 1483-1498. [CrossRef]

13. Barry, C.T.; Frick, P.J.; Grafeman, S.J. Child versus parent reports of parenting practices: Implications for the conceptualization of child behavioral and emotional problems. Assessment 2008, 15, 294-303. [CrossRef]

14. Collins, W.A.; Steinberg, L. Adolescent development in interpersonal context. In Handbook of Child Psychology, 6th ed.; Eisenberg, N., Ed.; John Wiley \& Sons: New York, NY, USA, 2006; Volume 3, pp. 1003-1067.

15. Sheehan, M.J.; Watson, M.W. Reciprocal influences between maternal discipline techniques and aggression in children and adolescents. Aggress. Behav. 2008, 34, 245-255. [CrossRef]

16. Garaigordobil, M.; Aliri, J. Parental socialization styles, parents' educational level, and sexist attitudes in adolescence. Span. J. Psychol. 2012, 15, 592-603. [CrossRef]

17. Martínez, I.; García, R.; Musitu, G.; Yubero, S. Family socialization practices: Factor confirmation of the Portuguese version of a scale for their measurement. J. Psychodidactics 2012, 17, 159-178. [CrossRef]

18. Heberle, A.E.; Brigg-Gowan, J.; Carter, A.S. A person-oriented approach to identifying parenting styles in mothers of early school-age children. Infant Child Dev. 2015, 24, 130-156. [CrossRef]

19. Serbin, L.A.; Karp, J. The intergenerational transfer of psychosocial risk: Mediators of vulnerability and resilience. Ann. Rev. Psychol. 2004, 55, 333-363. [CrossRef] [PubMed]

20. Wheeler, L.A.; Updegraff, K.A.; Crouter, A. Mexican-origin parents' work conditions and adolescents' adjustment. J. Fam. Psychol. 2015, 29, 447-457. [CrossRef] [PubMed]

21. Simpkins, S.D.; Bouffard, S.M.; Dearing, E.; Kreider, H.; Wimer, C.; Caronongan, P.; Weiss, H.B. Adolescent adjustment and patterns of parents' behaviors in early and middle adolescence. J. Res. Adolesc. 2009, 19, 530-557. [CrossRef]

22. Chung, H.L.; Steinberg, L. Relations between neighbourhood factors, parenting behaviours, peer deviance, and delinquency among serious juvenile offenders. Dev. Psychol. 2006, 42, 319-331. [CrossRef]

23. Cenk, D.S.; Demir, A. The relationship between parenting style, gender and academic achievement with optimism among Turkish adolescents. Curr. Psychol. 2016, 35, 720-728. [CrossRef]

24. García, F.; Gracia, E. The indulgent parenting style and developmental outcomes in South European and Latin American Countries. In Parenting across Cultures: Childrearing, Motherhood and Fatherhood in Non-Western Cultures; Selin, H., Ed.; Springer: Dordrecht, The Netherlands, 2014; Volume 7, pp. 419-434.

25. Grolnick, W.; Pomerantz, E. Issues and challenges in studying parental control: Toward a new conceptualization. Child Dev. Perspect. 2009, 3, 165-170. [CrossRef]

26. Blondal, K.; Adalbjarnardottir, S. Parenting practices and school dropout: A longitudinal study. Adolescence 2009, 44, 729-749.

27. Pinquart, M. Associations of parenting dimensions and styles with externalizing problems of children and adolescents: An updated meta-analysis. Dev. Psychol. 2017, 53, 873-932. [CrossRef]

28. Chao, R. Extending research on the consequences of parenting styles for Chinese Americans and European Americans. Child Dev. 2001, 72, 1832-1843. [CrossRef]

29. Aucoin, K.J.; Frick, P.J.; Bodin, S.D. Corporal punishment and child adjustment. J. Appl. Dev. Psychol. 2006, 27, 527-541. [CrossRef]

30. Lansford, J.E.; Deater-Deckard, K.; Dodge, K.A.; Bates, J.E.; Pettit, G.S. Ethnic differences in the link between discipline and later adolescent externalizing behaviors. J. Child Psychol. Psychiatry 2004, 45, 801-812. [CrossRef]

31. Nunes, C.; Bodden, D.; Lemos, I.; Lorence, B.; Jiménez, L. Parenting practices and quality of life in Dutch and Portuguese adolescents: A cross-cultural study. J. Psychodidactics 2014, 19, 327-346. [CrossRef]

32. Bornstein, M.H. Form and function: Implications for studies of culture and human development. Cult. Psychol. 1995, 1, 123-137. [CrossRef]

33. Deater-Deckard, K.; Lansford, J.E.; Malone, P.S.; Alampay, L.P.; Sorbring, E.; Bacchini, D.; Bombi, A.S.; Bornstein, M.H.; Chang, L.; Al-Hassan, S.M.; et al. The association between parental warmth and control in thirteen cultural groups. J. Fam. Psychol. 2011, 25, 790-794. [CrossRef]

34. Super, C.M.; Harkness, S. The developmental niche: A conceptualization at the interface of child and culture. Int. J. Behav. Dev. 1986, 9, 545-569. [CrossRef] 
35. García, F.; Fernández-Doménech, L.; Veiga, F.H.; Bono, R.; Serra, E.; Musitu, G. Parenting Styles and Parenting Practices: Analyzing current relationships in the Spanish Context. In Parenting: Cultural Influences and Impact on Childhood Health and Well-Being; García, F., Ed.; Nova Science Publishers, Inc.: Hauppauge, NY, USA, 2015; pp. 17-31.

36. Lorence, B.; Hidalgo, M.V.; Menéndez, S. Parenting style and adolescent adjustment in contexts at psychosocial risk: Evidence from Spanish families. In Parenting: Cultural Influences and Impact on Childhood Health and Well-Being; García, F., Ed.; Nova Science Publishers, Inc.: Hauppauge, NY, USA, 2015; pp. 77-99.

37. Bornstein, M.H. Cultural approaches to parenting. Parent Sci. Pract. 2012, 12, 212-221. [CrossRef]

38. Selin, H. Parenting across Cultures: Childrearing, Motherhood and Fatherhood in Non-Western Cultures; Springer: Dordrecht, The Netherlands, 2014.

39. Dwairy, M.; Achoui, M. Adolescents-family connectedness: A first cross-cultural research on parenting and psychological adjustment of children. J. Child Fam. Stud. 2010, 19, 8-15. [CrossRef]

40. Parra, A.; Sánchez-Queija, I.; García-Mendoza, M.C.; Coimbra, S.; Oliveira, J.E.; Díez, M. Perceived parenting styles and adjustment during emerging adulthood: A cross-national perspective. Int. J. Environ. Res. Publ. Health 2019, 16, 2757. [CrossRef]

41. IPFE. Available online: http://www.ipfe.org/Espa\%C3\%B1a/Documento/115 (accessed on 9 July 2020).

42. Flaquer, L. The articulation between family and the welfare state in the countries of southern Europe. Papers 2004, 73, 27-58.

43. Wall, K.; Gouveia, R. Changing meanings of family in personal relationships. Curr. Sociol. 2014, 62, 352-373. [CrossRef]

44. Moreno-Maldonado, C.; Jiménez-Iglesias, A.; Camacho, I.; Rivera, F.; Moreno, C.; Matos, M.G. Factors associated with life satisfaction of adolescents living with employed and unemployed parents in Spain and Portugal: A person focused approach. Child. Youth Serv. Rev. 2020, 110, 104740. [CrossRef]

45. Serrano, G.; El-Astal, S.; Faro, F. La adolescencia en España, Palestina y Portugal: Análisis comparativo [Adolescence in Spain, Palestine and Portugal: A comparative analysis]. Psicothema 2004, 16, 468-475.

46. European Social Survey Data. Available online: http://www.europeansocialsurvey.org (accessed on 2 March 2020).

47. Hudson, J.; Kühner, S. Fairness for Children: A League Table of Inequality in Child Well-Being in Rich Countries. Innocenti Report Card 13; UNICEF: Florence, Italy, 2020.

48. Nunes, C.; Hernando, Á.; Lemos, I.; Ayala-Nunes, L.; Oliva, C.R.; Coronado, C.M. Quality of life of Portuguese and Spanish adolescents. A comparative study between natives and immigrants. Cien. Saude Coletiva 2016, 21, 1137-1144. [CrossRef]

49. The European Kidscreen Group. The KIDSCREEN Questionnaires. Quality of Life Questionnaires for Children and Adolescents; Pabst Science Publ.: Lengerich, Germany, 2006.

50. Musitu, G. Family socialization and values in adolescents: An intercultural analysis. Anu. Psicol. 2000, 31, 15-32.

51. Garcia, F.; Serra, E.; Garcia, O.F.; Martinez, I.; Cruise, E. A third emerging stage for the current digital society? Optimal parenting styles in Spain, the United States, Germany, and Brazil. Int. J. Environ. Res. Publ. Health 2019, 16, 2333. [CrossRef]

52. Calafat, A.; García, F.; Juan, M.; Becoña, E.; Fernández-Hermida, J.R. Which parenting style is more protective against adolescent substance use? Evidence within the European context. Drug Alcohol Depend. 2014, 138, 185-192. [CrossRef]

53. Martinez, I.; Garcia, F.; Veiga, F.; Garcia, O.F.; Rodrigues, Y.; Serra, E. Parenting styles, internalization of values and self-esteem: A cross-cultural study in Spain, Portugal and Brazil. Int. J. Environ. Res. Publ. Health 2020, 17, 2370. [CrossRef]

54. Rodrigues, Y.; Veira, F.; Fuentes, M.C.; García, F. Parenting and adolescents's self-esteem: The Portuguese context. J. Psychodidactics 2013, 18, 395-416. [CrossRef]

55. López-Jáuregui, A.; Oliden, P.E. Adaptation of the ESPA-29 parental socialization styles scale to the Basque language: Evidence of validity. Span. J. Psychol. 2009, 12, 737-745. [CrossRef] [PubMed]

56. Nunes, C.; Luis, K.; Lemos, I.; Musitu, G. Características psicométricas da versão portuguesa da escala de socialização parental na adolescência ESPA-29 [Psychometric properties of the Portuguese version of the parental socialization scale in adolescence ESPA-29]. Psicol. Reflex Crit. 2015, 28, 253-260. [CrossRef]

57. Henry, D.B.; Tolan, P.H.; Gorman-Smith, D. Cluster analysis in family psychology research. J. Fam. Psychol. 2005, 19, 121-132. [CrossRef] [PubMed] 
58. Tabachnick, B.G.; Fidell, L.S. Using Multivariate Statistics, 5th ed.; Pearson Education: Boston, MA, USA, 2007.

59. IBM Corp. IBM SPSS Statistics for Windows, Version 24.0; IBM Corp.: Armonk, NY, USA, 2016.

60. García, F.; Gracia, E. Is always authoritative the optimum parenting style? Evidence from Spanish families. Adolescence 2009, 44, 101-131. [PubMed]

61. Rudy, D.; Grusec, J.E. Correlates of authoritarian parenting in individualist and collectivist cultures and implications for understanding the transmission of values. J. Cross Cult. Psychol. 2001, 32, 202-212. [CrossRef]

62. Bergman, L.R.; El-Khouri, B.M. A person-oriented approach: Methods for today and methods for tomorrow. New Dir. Child Adoles. 2003, 101, 25-38. [CrossRef]

63. Pereira, A.; Canavarro, C.; Cardoso, M.F.; Mendonça, D. Patterns of parental rearing styles and child behaviour problems among Portuguese school-aged children. J. Child Fam. Stud. 2009, 18, 454-464. [CrossRef]

64. Janssens, A.; Goossens, L.; Noortgate, W.V.D.; Colpin, H.; Verschueren, K.; Leeuwen, K.V. Parents' and adolescents' perspectives on parenting: Evaluating conceptual structure, measurement invariance, and criterion validity. Assessment 2015, 22, 473-489. [CrossRef]

65. Espino, J.M.G. Two sides of intensive parenting: Present and future dimensions in contemporary relations between parents and children in Spain. Childhood 2013, 20, 22-36. [CrossRef]

66. Richman, S.B.; Mandara, J. Do socialization goals explain differences in parental control between black and white parents? Fam. Relat. 2013, 62, 625-636. [CrossRef]

67. Ponzetti, J.J. Evidence-Based Parenting Education: A Global Perspective; Routledge/Taylor \& Francis Group: New York, NY, USA, 2016.

68. Van Ryzin, M.J.; Kumpfer, K.L.; Fosco, G.M.; Greenberg, M.T. Family-Based Prevention Programs for Children and Adolescents: Theory, Research, and Large-Scale Dissemination; Psychology Press: New York, NY, USA, 2016.

(C) 2020 by the authors. Licensee MDPI, Basel, Switzerland. This article is an open access article distributed under the terms and conditions of the Creative Commons Attribution (CC BY) license (http://creativecommons.org/licenses/by/4.0/). 